\title{
Cholinergic $\alpha 5$ nicotinic receptor is involved in the proliferation and invasion of human prostate cancer cells
}

\author{
JIN-CHUN QI ${ }^{1}$, WEN-YONG XUE ${ }^{1}$, YAN-PING ZHANG ${ }^{1}$, CHANG-BAO QU $^{1}$, BAO-SAI LU ${ }^{1}$, \\ YUE-WEI YIN ${ }^{1}$, KAI-LONG LIU ${ }^{1}$, DONG-BIN WANG ${ }^{1}$, WEI LI ${ }^{1}$ and ZONG-MAO ZHAO ${ }^{2}$ \\ Departments of ${ }^{1}$ Urology and ${ }^{2}$ Neurosurgery, The Second Hospital of Hebei Medical University, \\ Shijiazhuang, Hebei, P.R. China
}

Received May 8, 2019; Accepted October 30, 2019

DOI: 10.3892/or.2019.7411

\begin{abstract}
Nicotinic acetylcholine receptor (nAChR) subunit $\alpha 5$ ( $\alpha 5-\mathrm{nAChR})$ is involved in tumor cell proliferation, inhibition of apoptosis, progression of metastasis, and induction of angiogenesis in certain solid tumors. However, the role of $\alpha 5-\mathrm{nAChR}$ in prostate cancer cell growth and metastasis is unclear. In the present study, the role of $\alpha 5-\mathrm{nAChR}$ in cell proliferation, migration, invasion and apoptosis was investigated by silencing the expression levels of $\alpha 5-n A C h R$ in the prostate cancer cell lines DU145 and PC3. A siRNA oligonucleotide targeting $\alpha 5-\mathrm{nAChR}$ was designed. The cell proliferation of DU145 and PC3 cell lines was analyzed by the Cell Counting Kit-8 (CCK-8) assay. Cell migratory and invasive activities were determined using wound healing and Transwell assays, respectively. Western blot analysis was used to quantify $\alpha 5-\mathrm{nAChR}$, p-AKT and p-ERK1/2 levels in DU145 and PC 3 cells. Knockdown of $\alpha 5$-nAChR was associated with decreased cell proliferation, migration, invasion and increased apoptosis. In addition, decreased phosphorylation levels of AKT and ERK1/2 were revealed following $\alpha 5-\mathrm{nAChR}$ knockdown in DU145 and PC3 cells compared with those observed in the scramble control samples. The expression levels of the apoptosis-related proteins were altered following silencing of $\alpha 5-n A C h R$. In summary, the data indicated that $\alpha 5-n A C h R$ was involved in the proliferation and invasion of human prostate cancer cells.
\end{abstract}

\section{Introduction}

Prostate cancer is one of the most common malignant tumors and is ranked as the second cause of cancer-associated deaths in male patients in developed countries (1). Prostate cancer mainly develops due to a switch from androgen-dependent

Correspondence to: Professor Zong-Mao Zhao, Department of Neurosurgery, The Second Hospital of Hebei Medical University, 215 Heping Xi Road, Shijiazhuang, Hebei, P.R. China

E-mail: zzm692017@sina.com

Key words: prostate cancer, $\alpha 5-\mathrm{nAChR}$, proliferation, metastasis to androgen-independent growth (2). Nicotinic acetylcholine receptors (nAChRs) comprise ligand-gated ion channels, which consist of 5 subunits with 4 transmembrane domains in each subunit. The nicotinic acetylcholine receptor (nAChR) signaling pathway affects various cancer-associated pathways that are important in promoting tumor cell proliferation, metastasis and angiogenesis (3-8).

It has been revealed that the $\alpha 5$ subunit of the $\mathrm{nAChR}$ ( $\alpha 5-\mathrm{nAChR}$ ), a member of the nAChR subunit family, is closely associated with the incidence of lung cancer. The activation of $\alpha 5-\mathrm{nAChR}$ is involved in tumor growth and metastasis and is important in the formation, metastasis and recurrence of lung cancer $(9,10)$. Previous studies have demonstrated that $\alpha 5-\mathrm{nAChR}$ is associated with gastric cancer (11-17). For example, exposure of nicotine to gastric cancer cells inhibits the cisplatin-induced apoptosis via the $\alpha 5-\mathrm{nAChR} / \mathrm{AKT}$ signaling pathway (11). However, it is unknown whether $\alpha 5-n A c h R$ is involved in the progression of prostate cancer. Based on the aforementioned findings, the involvement of $\alpha 5-n A C h R$ in the incidence and progression of prostate cancer was examined. Therefore, in the present study, the expression levels of $\alpha 5$-nAChR were examined in prostate cancer and normal prostate tissues. The expression levels of $\alpha 5-\mathrm{nAChR}$ were upregulated in prostate cancer tissues. Furthermore, silencing of $\alpha 5-n A C h R$ expression significantly inhibited prostate cancer cell invasion and migration in vitro. In addition, previous studies have identified the downstream signaling pathways of $\alpha 5-\mathrm{nAchR}$, which are involved in prostate cancer progression.

\section{Materials and methods}

Cell culture. The human normal prostate epithelial cell line RWPE-1 and the androgen-independent prostate cancer cell lines PC3 and DU145 were used in the present study. The metastatic potential of DU145 is higher than that of the PC3 cell line. 293 cells were obtained from the Type Culture Collection of the Chinese Academy of Sciences. DU145 cells were maintained in RPMI-1640 medium (Gibco; Thermo Fisher Scientific, Inc.) supplemented with a combination of $1 \%$ penicillin and streptomycin in the presence of $10 \%$ fetal bovine serum (Gibco). Ham's F-12K (Kaighn's) Medium (Gibco; Thermo Fisher Scientific, Inc.) was used to culture 
PC3 cells with $1 \%$ penicillin and streptomycin and $10 \%$ fetal bovine serum in the culture medium. 293 cells were cultured in Dulbecco's Modified Eagle's Medium (DMEM) (Gibco; Thermo Fisher Scientific, Inc.) with a combination of $1 \%$ penicillin and streptomycin and $10 \%$ fetal bovine serum. All the cells were incubated in standard cell culture conditions with $5 \% \mathrm{CO}_{2}$ and $95 \%$ humidity at $37^{\circ} \mathrm{C}$.

Cell transfection. A siRNA oligonucleotide targeting $\alpha 5-n A C h R$ mRNA was synthesized by Shanghai Genepharma Co. Ltd. The sequence was as follows: 5'-CCCGCAAACUAC AAAAGUUTT-3'. A pair of scrambled control siRNAs with sequences different from those of the siRNA- $\alpha 5-n A C h R$ was designed. The pair of sequences was not homologous to any sequences found in GeneBank. When the cells reached $70-80 \%$ confluence, the transfection was conducted according to the transfection instructions. The cells were subsequently cultured under normal conditions for $36 \mathrm{~h}$ at $37^{\circ} \mathrm{C}$.

Tissue samples from patients and immunohistochemistry (IHC). IHC was performed in 8 normal prostate tissues (all male, aged 66.37 \pm 4.53 ) and the results were compared with the analysis performed in 36 prostate cancer samples (Table I). The clinicopathological variables of these patients were collected. Written informed consent forms were obtained from the subjects. The study protocol was approved by the Research Ethics Committee of the Second Hospital of Hebei Medical University. IHC was performed to determine $\alpha 5-\mathrm{nAChR}$ expression. Paraffin-embedded tissue sections $(5-\mu \mathrm{m}$ thick) were deparaffinized with xylene, followed by rehydration using a graded series of 100, 90, 80 and 70\% ethanol. Then, intrinsic peroxidase was deactivated with $0.3 \% \mathrm{H}_{2} \mathrm{O}_{2}$ and intrinsic biotin was deactivated with skim milk. The sections were reacted with the primary (cat. no. ab166718; Abcam) and secondary (cat. no. ab97048; Abcam) antibodies. Finally, $\mathrm{H}_{2} \mathrm{O}_{2}$ was added to DAB to undergo reaction. Sections were then stained with methyl green, and the target proteins were observed under a light microscope (magnification, x100 and x400).

Reverse transcription-quantitative polymerase chain reaction $(R T-q P C R)$. TRIzol reagent (CWBIO) was used to isolate total RNA as determined by the manufacturer's instructions. A total of 500 ng of RNA was extracted from each sample and reverse-transcribed using the Reverse Transcription Reaction Kit (CWBIO). The relative mRNA levels of $\alpha 5-n A C h R$, and $\beta$-actin (internal control) were determined by RT-qPCR using an FTC-3000 Real-Time PCR System. All real-time PCR assays used the SYBR Green Supermix. The cycles used for RNA amplification included a pre-denaturing step at $95^{\circ} \mathrm{C}$ for a duration of $10 \mathrm{sec}$, followed by 40 PCR cycles consisting of $5 \mathrm{sec}$ at $95^{\circ} \mathrm{C}, 30 \mathrm{sec}$ at $60^{\circ} \mathrm{C}$, and $10 \mathrm{~min}$ at $72^{\circ} \mathrm{C}$. All samples were repeatedly assayed in triplicate in each experiment. The relative amount of mRNA was determined by the comparative $\Delta \Delta \mathrm{Cq}$ method (18) and then normalized to the $\beta$-actin mRNA levels. The sequences of $\alpha 5-n A C h R$ primers were as follows: Forward, GACTCCACCGGCAAACTACA and reverse, TTT GCTCCCTGTTGCACTCA.

Western blotting. The cells were treated with PBS and subsequently lysed in RIPA buffer (Beyotime Institute of
Biotechnology). Then the protein concentration was determined by the Pierce BCA Protein Assay (Thermo Fisher Scientific, Inc.). In each sample, $44 \mu \mathrm{g}$ protein was resolved by gel electrophoresis using $15 \%$ sodium dodecyl sulfate (SDS)-polyacrylamide gels. The proteins were transferred to a PVDF membrane, and finally analyzed by western blotting. The primary antibodies against $\alpha$-tubulin (cat. no. ab18251) and anti- $\alpha 5-n A C h R$ (cat. no. ab166718) (rabbit polyclonal antibody) and the secondary alkaline phosphatase-coupled anti-rabbit IgG antibody (cat. no. ab97048) were obtained from Abcam. The membranes were blocked in 5\% fat-free milk in TBS containing $0.1 \%$ Tween-20 at room temperature for $1 \mathrm{~h}$ and subsequently incubated with primary antibodies against tubulin (1:10,000 dilution) and $\alpha 5$-nAChR (1:1,000 dilution) for $2 \mathrm{~h}$. The membranes were further incubated with secondary antibodies $(1: 5,000)$ for $1 \mathrm{~h}$. The western blot assay was repeated 3 times in order to evaluate the repeatability of the procedure. Finally, the labeled proteins were detected by chemiluminescence (ECLPlus; Amersham Pharmacia Biotech; GE Healthcare) and analyzed using ImageJ software (v1.43; National Institutes of Health).

Cell Counting Kit-8 (CCK-8) assay. PC3 and DU145 cells were cultured in a 96-well plate at a density of 1,000 cells/well. The cells were divided into the control (si-RNA-NC, scramble sequence) and the test groups (si- $\alpha 5-n A C h R)$. The cell proliferation assay was performed as follows: A total of $10 \mu \mathrm{l} \mathrm{CCK-8}$ solution (Beijing Solarbio Science \& Technology Co., Ltd.) was added to each well and the plate was incubated at $37^{\circ} \mathrm{C}$ for $2 \mathrm{~h}$. A microplate reader was used to measure the absorbance at $450 \mathrm{~nm}$.

Transwell assay. The cell migration assay was conducted using Transwell chambers. The Transwell inserts were placed in 24 well plates (Corning, Inc.). Following treatment with either full-length $\alpha 5$-nAChR plasmid or $\alpha 5$-nAChR-specific siRNA, $5 \times 10^{4}$ cells/well were placed in the upper chamber with $200 \mu \mathrm{l}$ culture medium (RPMI-1640 medium for DU145 and Ham's F-12K for PC3). The lower chamber was filled with $600 \mu \mathrm{l}$ of 10\% FBS culture medium (RPMI-1640 medium for DU145 and Ham's F-12K for PC3). The cells were then cultured for $24 \mathrm{~h}$. The outer surface was subsequently washed three times with PBS, fixed with methanol for $20 \mathrm{~min}$ and stained with $0.2 \%$ crystal violet for $15 \mathrm{~min}$ at room temperature. The images were obtained immediately after drying. The number of migrated cells were counted in five randomly microscopic fields of view (Olympus Corp.) at x400 magnification. The experiments were repeated three times and the data were summarized.

TUNEL assay. One-Step TUNEL kit (Beyotime Institute of Biotechnology) was used following the manufacturer's recommendations. Briefly, PC3 and DU145 cells were exposed to si-RNA-NC (scramble sequence) or si- $\alpha 5-\mathrm{nAChR}$ for $24 \mathrm{~h}$ and then fixed in $4 \%$ paraformaldehyde for $10 \mathrm{~min}$ at room temperature. Subsequently, the cells were washed with PBS three times and permeabilized for $2 \mathrm{~min}$ on ice and then the cells were resuspended in TUNEL working solution. Following incubation for $1 \mathrm{~h}$ in a humidified atmosphere at $37^{\circ} \mathrm{C}$ in the dark, the cells were counterstained with DAPI 
Table I. Expression of $\alpha 5-n A C h R$ in prostate tissue from prostate cancer patients.

\begin{tabular}{|c|c|c|c|c|}
\hline Clinical characteristics & Case no. (n) & $\alpha 5-n A C h R$ low expression (n) & $\alpha 5-n A C h R$ high expression (n) & P-value \\
\hline \multicolumn{5}{|l|}{ Age } \\
\hline$\leq 60$ & 15 & 8 & 7 & 0.5348 \\
\hline$>60$ & 21 & 9 & 12 & \\
\hline \multicolumn{5}{|l|}{ Tumor diameter (cm) } \\
\hline$\leq 3.0$ & 19 & 7 & 4 & 0.1907 \\
\hline$>3.0$ & 17 & 10 & 15 & \\
\hline \multicolumn{5}{|l|}{ Lymph-node metastasis } \\
\hline Yes & 4 & 2 & 2 & 0.906 \\
\hline No & 32 & 15 & 17 & \\
\hline
\end{tabular}

$\alpha 5-\mathrm{nAChR}$, nicotinic acetylcholine receptor subunit $\alpha 5$.

staining solution for $5 \mathrm{~min}$ at room temperature, DAPI was used for the nuclear staining and afterwards washed with PBS. The staining solution consisted of a mixture of methanol and DAPI as follows: $1 \mathrm{ml}$ methanol and $2 \mu \mathrm{l}$ DAPI (from a stock solution of $1 \mathrm{mg} / \mathrm{ml}$ ). The mounting medium was S2100 (Solarbio Science and Technology Co., Ltd.). The number of TUNEL-positive cells were counted in five randomly fluorescence microscopic fields of view. The experiments were repeated three times and the data were summarized.

Wound healing assay. The cells were transfected by siRNA targeting $\alpha 5$ - $n A C h R$ mRNA using NanoFectin Transfection Reagent. Following $24 \mathrm{~h}$ of incubation, a scratch was made to the bottom of the culture dish by the tip of a glass micropipette in order to establish a clean wound area. The cultured cells were maintained in their original culture medium. The culture dish with the scratched wound was photographed at the following time-points: 0, 12 and $24 \mathrm{~h}$ after the wound was made.

Statistical analysis. The data were expressed as the mean \pm SD and were analyzed using SPSS v17 (SPSS, Inc.). Pearson's chi-squared test was performed to examine the correlation of $\alpha 5-n A C h R$ expression with the various clinical factors. One-way ANOVA was performed to determine the differences between the experimental groups, and the least significant difference (LSD) post hoc test was used. A P-value $<0.05(\mathrm{P}<0.05)$ was considered to indicate a statistically significant difference.

\section{Results}

$\alpha 5-n A C h R$ is overexpressed in prostate cancer. To investigate the expression levels of $\alpha 5-n A C h R$ in prostate cancer tissues, RT-PCR was initially used and the $\alpha 5-n A C h R$ mRNA levels were analyzed in 2 human prostate cancer cell lines. The results were compared with the human prostate epithelial cell line RWPE-1. The mRNA levels of $\alpha 5-n A C h R$ in the prostate cancer cell lines (PC3 and DU145) were higher than those noted in the normal prostate epithelial cell line (RWPE-1) (Fig. 1A). $\alpha 5$-nAChR protein expression was further assessed in the PC3 and DU145 cancer cell lines and in the normal prostate epithelial cell line RWPE-1 by western blotting. A similar expression pattern was noted to that observed for the mRNA expression (Fig. 1B and C).

Subsequently, IHC analysis was performed to examine the $\alpha 5-n A C h R$ expression levels in a tissue array consisting of 8 normal prostate tissues compared with those noted in 36 prostate cancer samples (Fig. 1D). The expression levels of $\alpha 5-\mathrm{nAChR}$ in prostate cancer tissues were increased $(\mathrm{P}=0.0384)$. Subsequently, the correlation between the levels of $\alpha 5-n A C h R$ expression and the clinicopathological variables of prostate cancer patients was evaluated. The expression levels of $\alpha 5$-nAChR were not associated with the parameters age, lymph-node metastasis and tumor diameter (Table I).

$\alpha 5-n A C h R$ promotes proliferation and migration of human prostate cancer cells. The initial experiments demonstrated that the $\alpha 5-n A C h R$ expression levels were different between prostate cancer and normal tissues. Additional experiments focused on identifying whether $\alpha 5-\mathrm{nAChR}$ could promote the proliferation and migration of prostate cancer cells and therefore contribute to the progression of prostate cancer. To determine the role of $\alpha 5-n A C h R$ in the biological behavior of prostate cancer cells, siRNA sequences of $\alpha 5-n A C h R$ were transfected into 3 cell lines (PC3, DU145 and RWPE-1). RT-qPCR was used to detect the transfection efficiency. si- $\alpha 5-n A C h R$ caused a significant inhibition in the expression levels of $\alpha 5-n A C h R$ in PC3, DU145 and RWPE-1 cells (Fig. 2A).

The effect of $\alpha 5-n A C h R$ on the growth of prostate cancer cells was determined using a CCK-8 assay. The proliferation of DU145 cells transfected with $\alpha 5$-nAChR-specific siRNA was signficantly reduced (Fig. 2B). The effects of $\alpha 5$-nAChR-siRNA on DU145 cell proliferation indicated successful transfection of $\alpha 5-n A C h R$ siRNA in prostate cancer cells in vitro. Clone formation assays of PC3 and DU145 cells indicated that the clone number of the si- $\alpha 5-\mathrm{nAChR}$-treated cells decreased significantly compared with that of the NC cells (Fig. 2C and D).

Subsequently, the wound healing assay indicated that overexpression of $\alpha 5-n A C h R$ markedly promoted cell migration into the wound areas compared with that of the negative control (NC) cells. Downregulation of $\alpha 5-n A C h R$ by si-RNA significantly inhibited the migratory activities of DU145 cells that expressed high levels of $\alpha 5-n A C h R$ (Fig. 3A and B). 


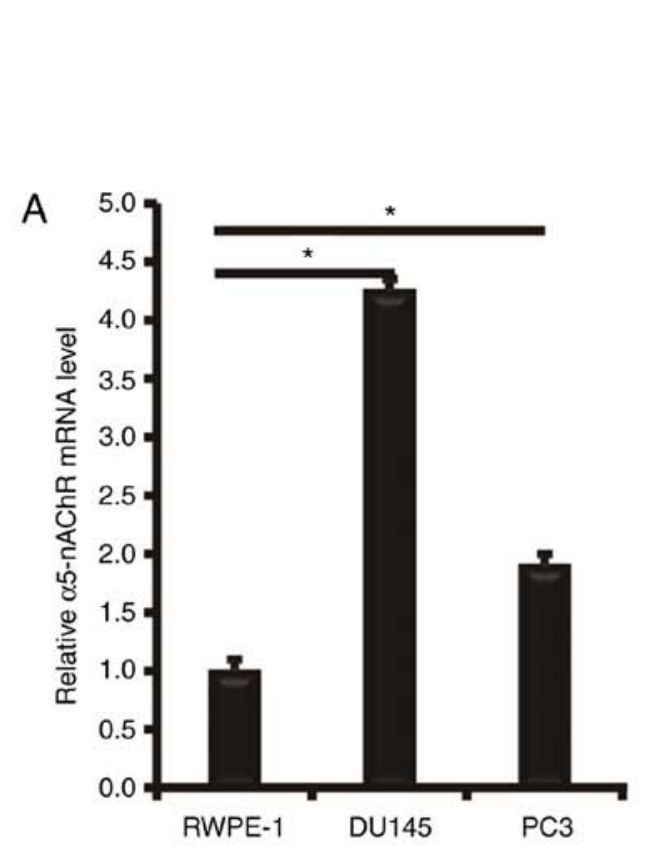

D

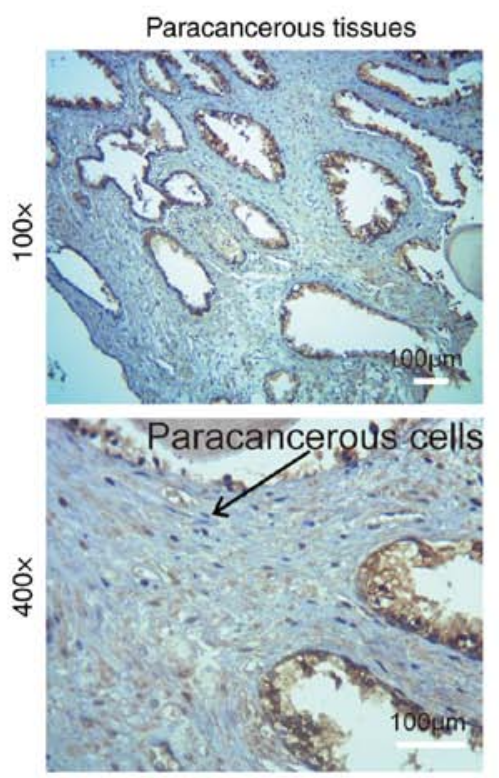

B

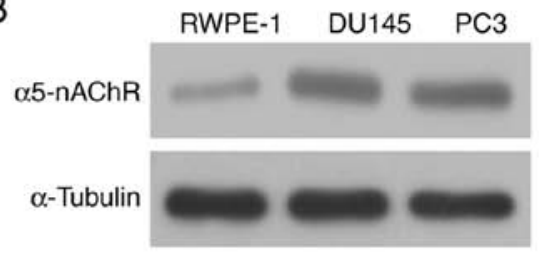

C

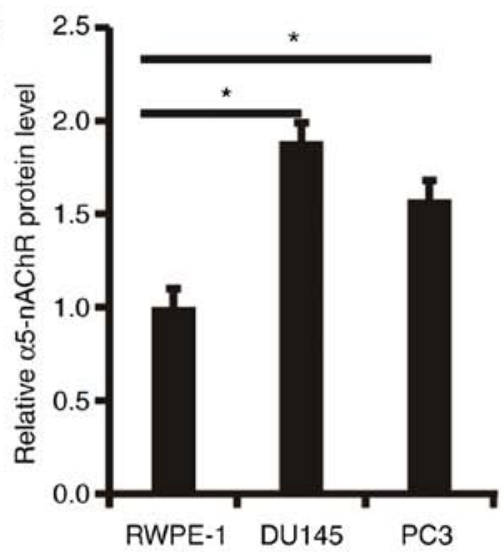

Prostate cancer tissues

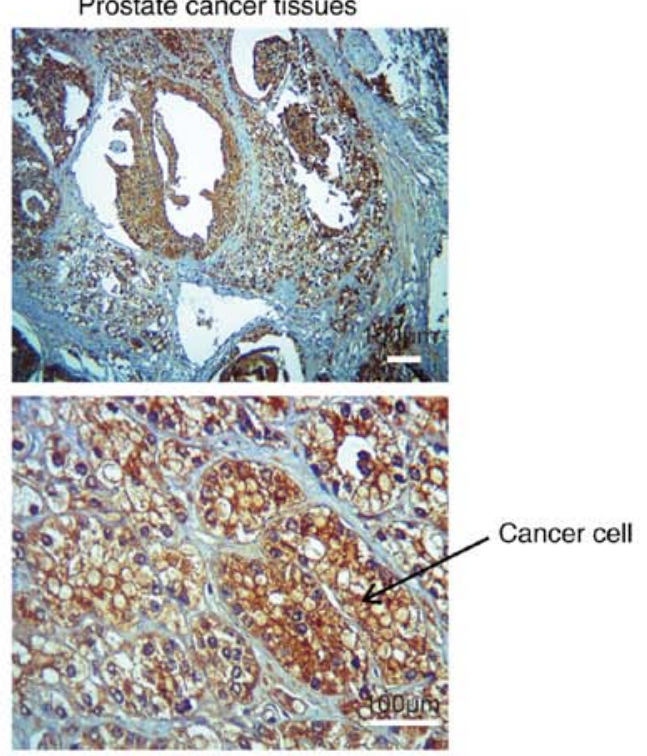

Figure 1. $\alpha 5-\mathrm{nAChR}$ is overexpressed in prostate cancer. (A) RT-qPCR was performed to detect $\alpha 5-n A C h R$ mRNA levels in the two prostate cancer cell lines, PC3 and DU145, and in the normal prostate cell line RWPE-1 that was used as a control. (B) $\alpha 5$-nAChR protein levels in PC3, DU145 and RWPE-1 cells were evaluated by western blotting. (C) The relative protein levels of $\alpha 5$-nAChR were evaluated based on triplicate experiments and analyzed by the ImageJ software. (D) $\alpha 5$-nAChR expression in human prostate cancer was detected by IHC analysis in a tissue array. Representative micrographs of normal and cancer tissues are presented. $\mathrm{P}<0.05$. $\alpha 5$-nAChR, nicotinic acetylcholine receptor subunit $\alpha 5$.

The migratory activity of the cells transfected with either full-length $\alpha 5$-nAChR plasmid or $\alpha 5$-nAChR-specific siRNA was evaluated. When the cells were transfected with the $\alpha 5$-nAChR vector, their migratory activity into the lower chamber was increased (Fig. 3C and D). The cells transfected with $\alpha 5$-nAChR-specific siRNA demonstrated reduced migratory activity into the lower chamber. This finding suggested that $\alpha 5-\mathrm{nAChR}$ could promote the migratory activity of the DU145 prostate cancer cells.

a5-nAChR inhibits the induction of apoptosis of human DU145 and PC 3 cells. The induction of apoptosis was detected by the TUNEL assay. The experimental results indicated that downregulation of $\alpha 5-n A C h R$ with siRNA- $\alpha 5-n A C h R$ increased the number of apoptotic cells compared with that of the control group ( $\mathrm{P}<0.05$, Fig. $4 \mathrm{~A}$ and $\mathrm{B})$.

Since cleaved caspase- 3 expression is positively associated with cell apoptosis, the role of $\alpha 5-n A C h R$ in cell apoptosis was detected by western blot analysis of caspase-3 and cleaved caspase-3. The expression levels of total caspase-3 and cleaved caspase- 3 were determined in DU145 and PC3 cells treated with control si-RNA-NC and siRNA- $\alpha 5-n A C h R$. Silencing of $\alpha 5-n A C h R$ expression by siRNA- $\alpha 5-n A C h R$ decreased the expression levels of total caspase- 3 and 

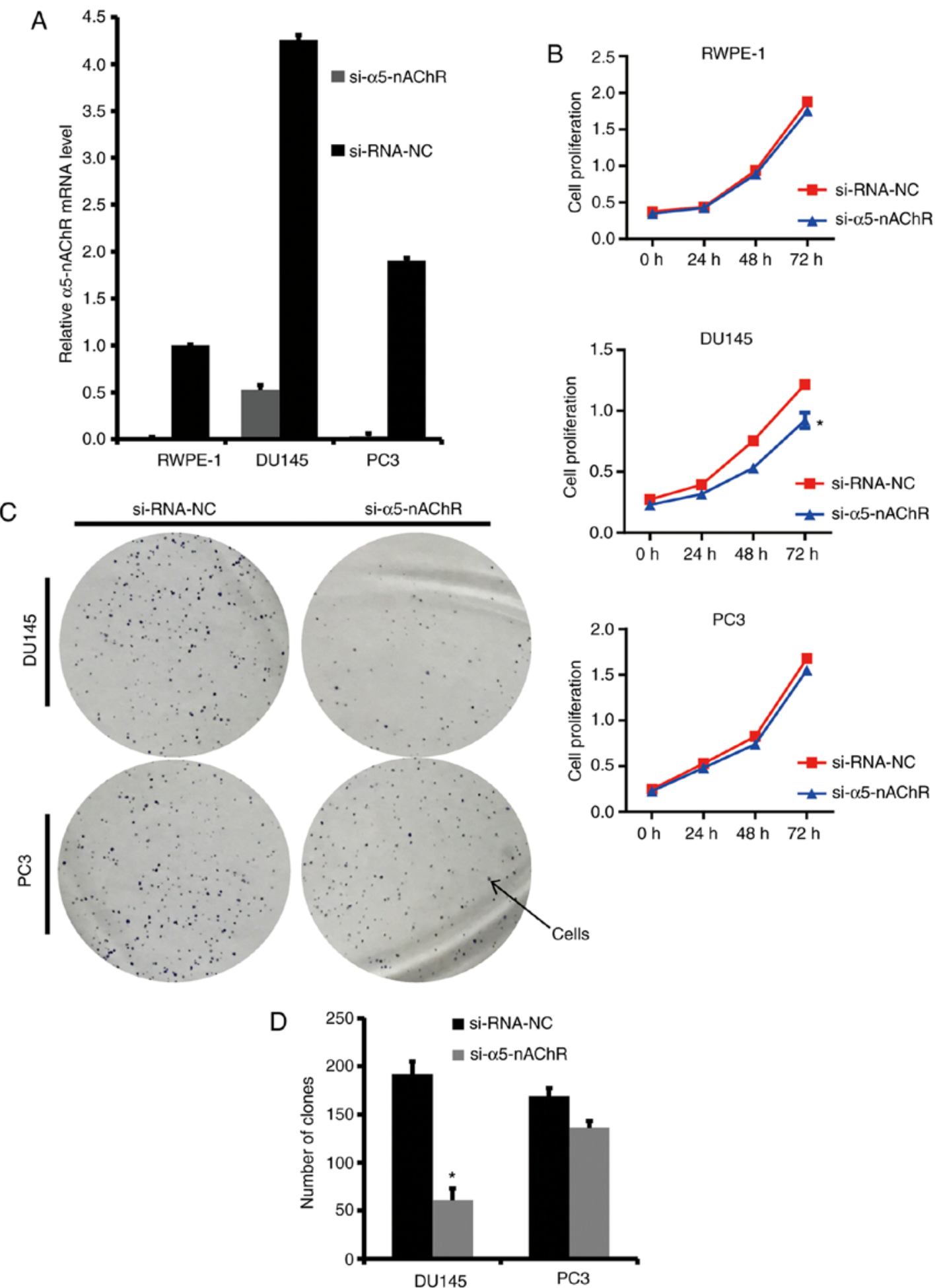

Figure 2. Knockdown of $\alpha 5$-nAChR inhibits the proliferation of human prostate cancer cells. (A) The efficiency of $\alpha 5$-nAChR knockdown was determined by RT-qPCR. si- $\alpha 5$-nAChR caused a significant inhibition in the expression levels of $\alpha 5$-nAChR in PC3, DU145 and RWPE-1 cells. (B) A CCK-8 assay was performed as described in the Materials and methods section in order to detect the proliferation of the NC- and of the si- $\alpha 5$-nAChR-transfected prostate cancer cells. (C) Clone formation assays of PC 3 and DU145 cells. (D) The number of clones in the si- $\alpha 5$-nAChR-treated cells was significantly decreased compared with that of the NC cells. "P<0.05. $\alpha 5$-nAChR, nicotinic acetylcholine receptor subunit $\alpha 5$; CCK-8, Cell Counting Kit-8; NC, negative control.

increased the expression levels of cleaved caspase-3 $(\mathrm{P}<0.05)$ (Fig. 4C and D).

Downregulation of $\alpha$ 5-nAChR expression alters the phosphorylation status of ERK1/2 and AKT. It has been revealed that upon binding to nicotine, nAChRs activate the ERK and PI3K/AKT signaling pathways in several human cancer cells. The levels of total ERK1/2 and phosphorylated ERK1/2 and levels of total AKT and phosphorylated were analyzed following transfection of DU145 and PC3 cancer cells with siRNA- $\alpha 5-n A C h R$ (Fig. 5A and B). The phosphorylation levels of p-ERK1/2 and p-AKT were significantly decreased by downregulation of 
A

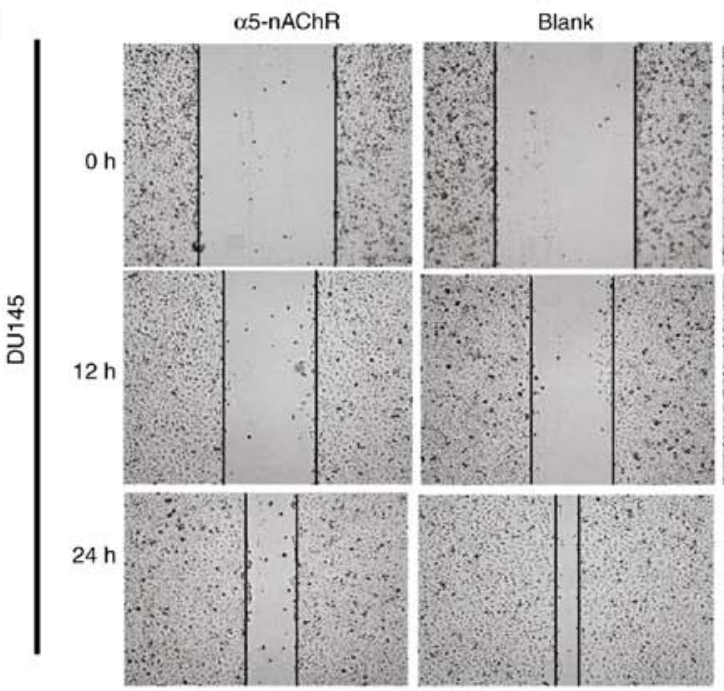

C

DU145

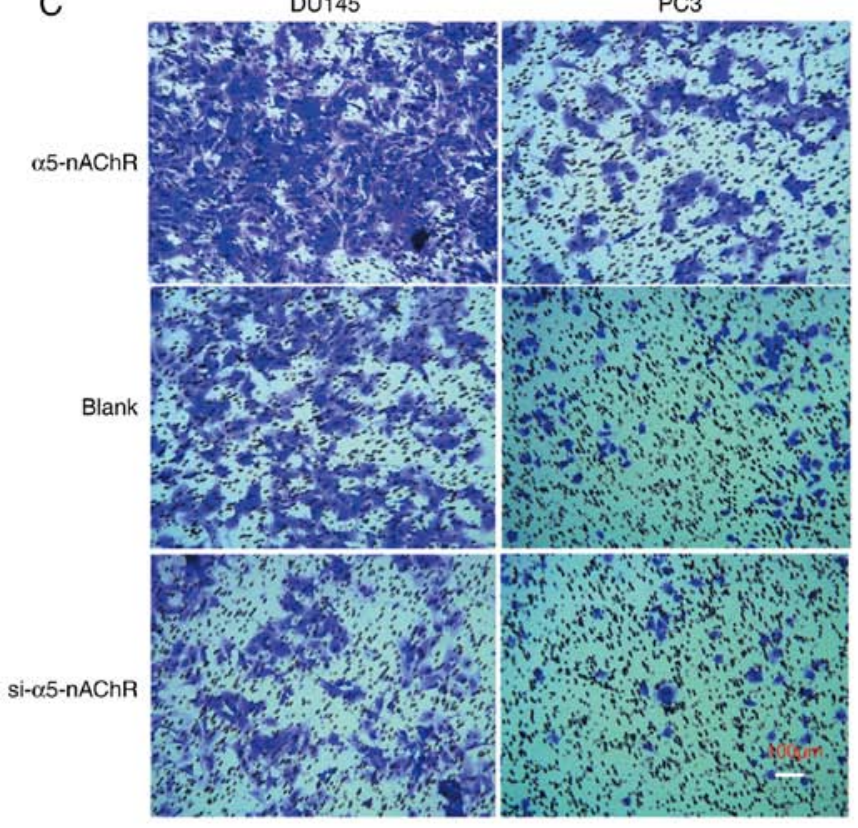

si- $\alpha 5-n A C h R$
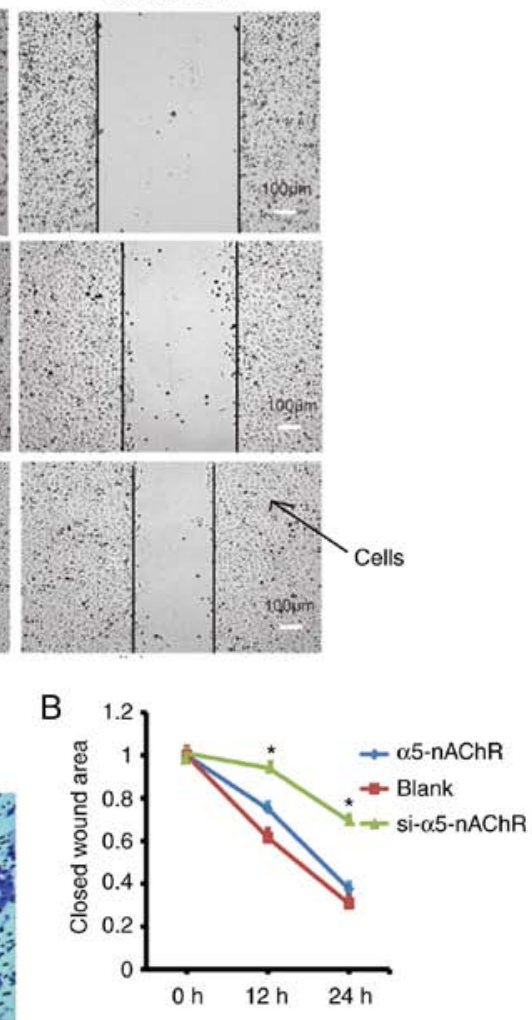

D

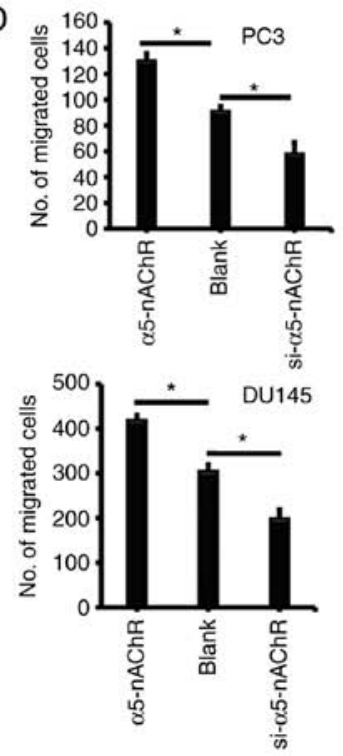

Figure 3. $\alpha 5-\mathrm{nAChR}$ promotes the migration of human prostate cancer cells. (A) A wound healing assay was performed to detect the migratory abilities of the NC cells, cells transfected with a full-length $\alpha 5$-nAChR plasmid or cells transfected with si- $\alpha 5-n A C h R$. (B) Quantified results of the wound healing assay in A. $\alpha 5$-nAChR promoted the migration of DU145 cells. (C) Transwell assays were performed as described in the Materials and methods section. The number of migrated cells was estimated from 5 randomly selected fields. (D) $\alpha 5$-nAChR promoted the migration of PC3 and DU145 cells. "P<0.05. $\alpha 5$-nAChR, nicotinic acetylcholine receptor subunit $\alpha 5$; NC, negative control.

a5-nAChR (Fig. 5C and D). The results indicated that phosphorylation of ERK and AKT proteins was involved in the A5-nAChR-mediated abnormal growth of prostate cancer cells.

\section{Discussion}

Smoking is an independent risk factor for several tumors and has further been studied as a risk factor for prostate cancer (19-22). However, the results are inconsistent. Some studies have revealed that the risk of prostate cancer increases with increasing smoking frequency, which is considered an independent risk factor for this disease (23-25). In contrast to these findings, a numerous studies have revealed no significant correlation between the smoking incidence and the incidence of prostate cancer, although several studies have revealed a high mortality percentage due to prostate cancer in patients who smoke (26-28). A possible explanation may be the presence of specific compounds in cigarettes that do not necessarily lead to 
A
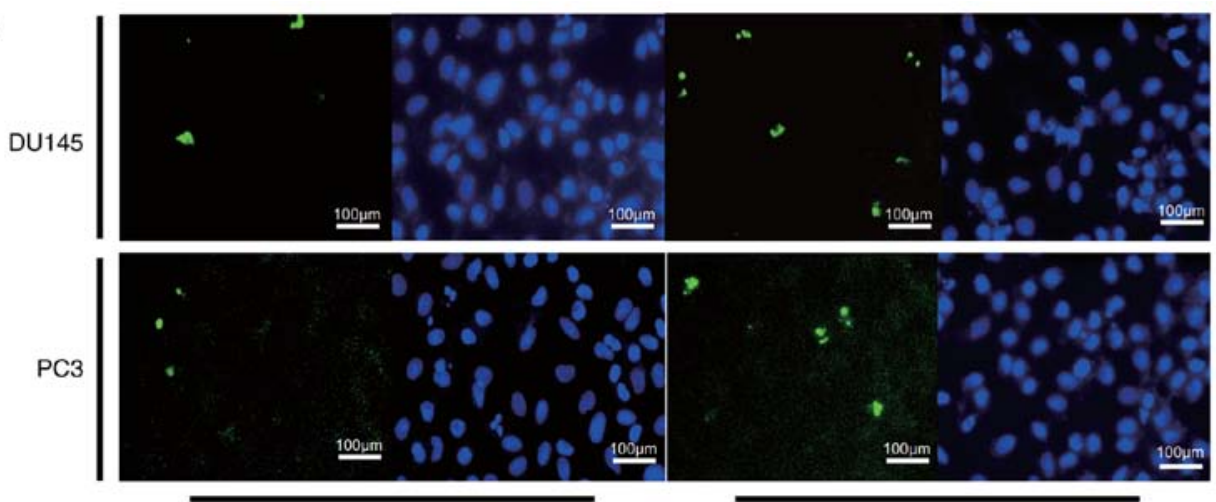

si-RNA-NC

si- $\alpha 5-n A C h R$
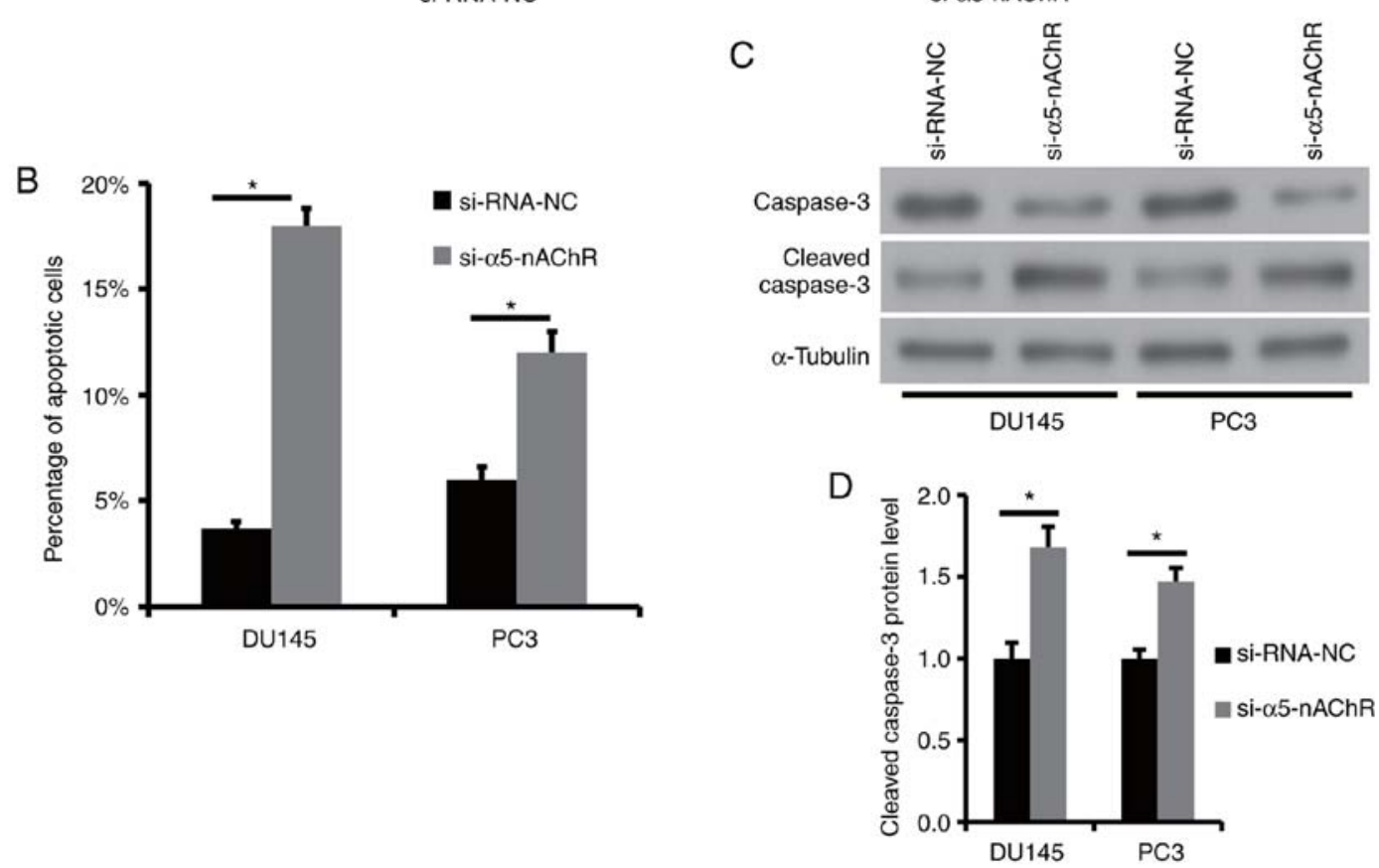

Figure 4. Knockdown of $\alpha 5$-nAChR induces apoptosis of human prostate cancer cells. (A) A TUNEL assay was performed to detect the number of apoptotic cells in the NC and si- $\alpha 5-n A C h R$ groups. Representative fluorescence micrographs are presented. (B) The percentage of apoptotic cells was increased when the expression levels of $\alpha 5-\mathrm{nAChR}$ were suppressed. (C) The expression levels of the apoptosis-related proteins were confirmed using western blotting. (D) Statistical analysis of western blotting results was performed using the ImageJ software. ${ }^{*} \mathrm{P}<0.05$. $\alpha 5$-nAChR, nicotinic acetylcholine receptor subunit $\alpha 5$; NC, negative control.

the cancer, but affect the cellular behavior of cancer cells and accelerate the progression of cancer. According to previous studies, it is speculated that nicotine, which is a carcinogenic compound found in cigarettes, may cause cancer progression by mimicking the biological function of acetylcholine and by binding to the $\mathrm{nAChR}$, which subsequently causes a series of signaling cascades within the cell. $\alpha 5-\mathrm{nAChR}$ is a regulatory subunit of $\mathrm{nAChR}$ and is involved in the growth and metastasis of solid tumors, such as lung and gastric cancers. This subunit is a promising therapeutic target for human tumors. In the present study, it was speculated that $\alpha 5-\mathrm{nAChR}$ may be associated with the progression of prostate cancer.

Initial experiments demonstrated that $\alpha 5$-nAChR expression was increased in prostate cancer cell lines and cancer tissues compared with that observed in normal prostate cell lines and the corresponding adjacent tissues. The molecular mechanism underlying the upregulation of $\alpha 5-n A C h R$ in prostate cancer is complex. The gene cluster encoding $\mathrm{nAChR}$ and CHRNA5/A3/B4 is located on the 15q24-25 region and is co-expressed in a variety of cell types $(29,30)$. The promoter region contains a GC structure, which has multiple transcription factor binding sites. The transcription of these 3 genes may be regulated by various transcription factors (31). Noatbly, the transcriptional direction for $\alpha 5-\mathrm{nAChR}$ is opposite to that of the A3 and B4 subunits, indicating that in addition to regulating the entire gene cluster, a distinct transcriptional regulatory mechanism may exist for $\alpha 5-\mathrm{nAChR}$ expression. The mechanism of the regulation of $\alpha 5-\mathrm{nAChR}$ expression is poorly understood compared with the evidence presented on the other subunits of $\mathrm{nAChR}$.

In the present study, the data confirmed that $\alpha 5-n A C h R$ could promote the proliferation and migration of prostate cancer cells. The opposite effect was noted for the induction of apoptosis, which was inhibited in prostate cancer cells. The function of $\alpha 5-\mathrm{nAChR}$ in tumors is not widely studied compared with the other subunits of $n A C h R$. To the best of our knowledge, $\alpha 5-\mathrm{nAChR}$ is upregulated and can promote tumor growth and metastasis in lung and gastric cancers. The 
A

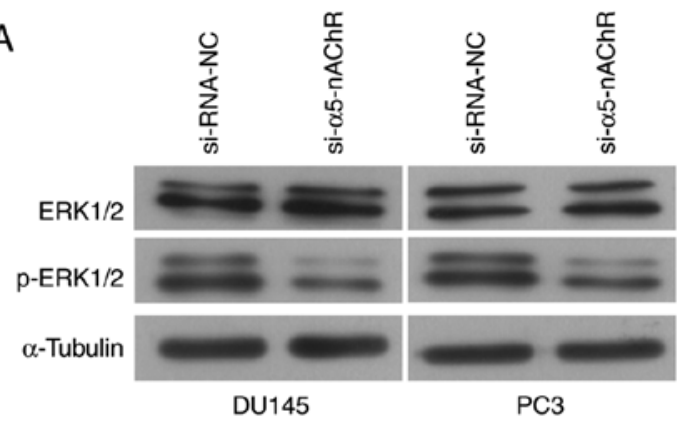

C

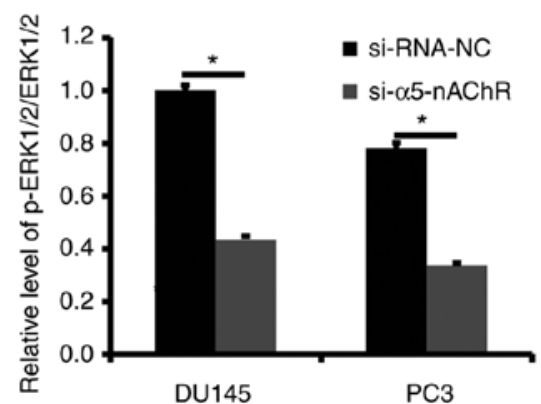

B

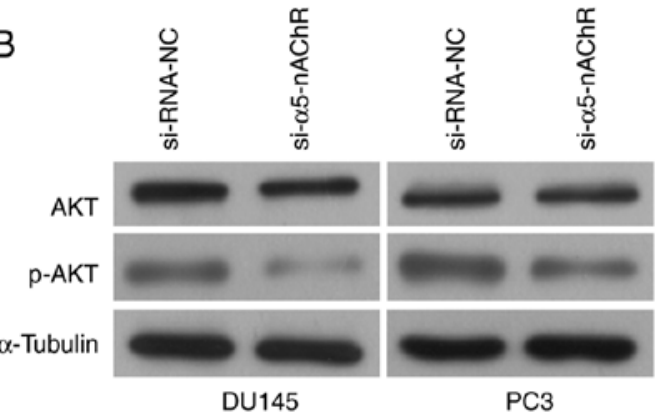

D

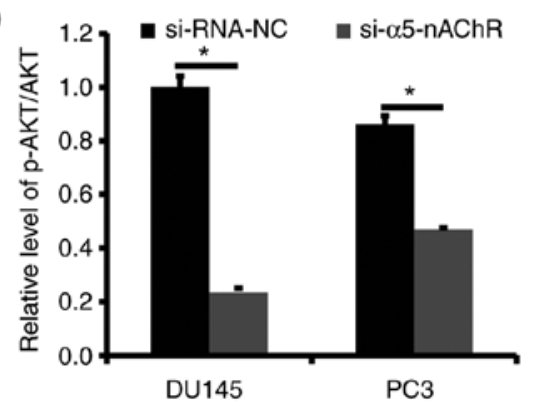

Figure 5. Knockdown of $\alpha 5$-nAChR inhibits the activation of the ERK1/2 and AKT pathway in prostate cancer cells. (A) Western blot analysis of total ERK1/2 and p-ERK1/2 expression in PC3 and DU145 cells. (B) Western blot analysis of total AKT and p-AKT expression in PC3 and DU145 cells. (C) Statistical analysis of the western blotting results was performed using the ImageJ software. Downregulation of $\alpha 5-\mathrm{nAChR}$ by si- $\alpha 5$-nAChR inhibited the phosphorylation levels of ERK1/2. (D) si- $\alpha 5-n A C h R$ further inhibited the phosphorylation levels of AKT. $\mathrm{P}<0.05$. $\alpha 5$-nAChR, nicotinic acetylcholine receptor subunit $\alpha 5$; p-ERK1/2, phosphorylated ERK1/2; p-AKT, phosphorylated AKT; NC, negative control.

results from previous studies are consistent with our findings. In the present study, silencing of $\alpha 5-\mathrm{nAChR}$ inhibited only the proliferation of the prostate cancer cell line DU145 and exhibited little or no effect on the proliferation of the prostate cancer cell line PC3. Both PC3 and DU145 cell lines are androgen-independent prostate cancer cell lines. However, their cellular response to exogenous stimuli may be distinct. For example, the metastatic potential of DU145 cells is higher than that of PC3 cells. Knockdown of $\alpha 5-n$ AChR did not influence the proliferation of PC3 cells but inhibited cell proliferation of DU145 cells. The data indicated that $\alpha 5-\mathrm{nAChR}$ played a significant role in promoting cell proliferation of certain prostate cancer cell types.

The data demonstrated that $\alpha 5-\mathrm{nAChR}$ promoted the development of prostate cancer by activating the PI3K/AKT signaling pathway, which has been revealed to play an important role in cancer progression by previous studies $(32,33)$. Activation of AKT is associated with the clinical characteristics of prostate cancer. A previous study revealed that the activated AKT levels are higher in poorly differentiated prostate cancer compared with those observed in highly and moderately differentiated prostate cancer (34). The activation of AKT was positively correlated with the prognosis of prostate cancer (35). Moreover, AKT activation was correlated with prostate cancer progression and androgen independence (36). The transcriptional activity, expression and even stability of the AR are regulated by the PI3K/AKT signaling pathway (37). The inhibition of the AKT pathway by siRNA interference or by a PI3K inhibitor leads to the inactivation of the HER2/neu-activated AR signaling pathway. This process is not affected by AR expression. In addition, nicotine increases AKT phosphorylation in a PI3K-dependent manner, suggesting that smoking causes bladder cancer progression via nicotine-induced activation of the PI3K/AKT pathway (38). In addition to the action of the PI3K/AKT pathway, $\alpha 5-\mathrm{nAChR}$ can act via the ERK1/2 pathway, which is activated in $30 \%$ of all human cancers. It has been revealed that increased activation of ERK can inhibit apoptosis induction by endoplasmic reticulum stress in order to promote cell survival. In the present study, downregulation of $\alpha 5-\mathrm{nAChR}$ decreased the phosphorylated levels of the ERK1/2 protein in the DU145 and PC 3 cell lines. Based on these results, it was speculated that $\alpha 5-\mathrm{nAChR}$ may also be a target for nicotine that could promote prostate cancer progression. However, this hypothesis requires further confirmation.

In conclusion, the data demonstrated for the first time that $\alpha 5-n A C h R$ levels were increased in prostate cancer samples and that they could promote the proliferation and migration of prostate cancer cells by the activation of the AKT signaling pathway. This finding provides clinically relevant information on utilizing $\alpha 5-\mathrm{nAChR}$ as a novel biomarker in order to improve prostate cancer prognosis. The present study provides a rational to develop new therapeutic approaches in order to suppress the proliferation and invasion of prostate cancer cells.

\section{Acknowledgements}

Not applicable.

\section{Funding}

Internal funding was received for the present study from the Second Hospital of the Hebei Medical University. 


\section{Availability of data and materials}

The datasets used during the present study are available from the corresponding author upon reasonable request.

\section{Authors' contributions}

JCQ designed and performed the experiments, wrote the manuscript. WYX, YPZ, CBQ, BSL, YWY, KLL, DBW and WL contributed to experimental work and data analysis. ZMZ conducted the experiments and wrote the manuscript. All authors have read and approved the final manuscript and agree to be accountable for all aspects of the research in ensuring that the accuracy or integrity of any part of the work are appropriately investigated and resolved.

\section{Ethics approval and consent to participate}

The study protocol was approved by the Research Ethics Committee of the Second Hospital of Hebei Medical University. Written informed consent forms were obtained from the subjects.

\section{Patient consent for publication}

Not applicable.

\section{Competing interests}

The authors declare that they have no competing interests.

\section{References}

1. Reiter RE: Risk stratification of prostate cancer 2016. Scand J Clin Lab Invest Suppl 245 (Suppl): S54-S59, 2016.

2. Li HZ and Zhang YS: Review of hot topics in the diagnosis and treatment of prostate cancer in 2016. Zhonghua Wai Ke Za Zhi 55: 59-62, 2017 (In Chinese).

3. Brown KC, Perry HE, Lau JK, Jones DV, Pulliam JF, Thornhill BA, Crabtree CM, Luo H, Chen YC and Dasgupta P: Nicotine induces the up-regulation of the $\alpha 7$-nicotinic receptor $(\alpha 7-n A C h R)$ in human squamous cell lung cancer cells via the Spl/GATA protein pathway. J Biol Chem 288: 33049-33059, 2013.

4. Cesario A, Russo P, Nastrucci C and Granone P: Is $\alpha 7-n A C h R$ a possible target for lung cancer and malignant pleural mesothelioma treatment? Curr Drug Targets 13: 688-694, 2012.

5. Guo L, Wu Z and Zhou Q: Roles of nicotine and nicotinic acetylcholine receptors (nAChR) in carcinogenesis and development of lung cancer. Zhongguo Fei Ai Za Zhi 14: 753-757, 2011 (In Chinese).

6. Li H, Wang S, Takayama K, Harada T, Okamoto I, Iwama E, Fujii A, Ota K, Hidaka N, Kawano Y and Nakanishi Y: Nicotine induces resistance to erlotinib via cross-talk between $\alpha 1 \mathrm{nAChR}$ and EGFR in the non-small cell lung cancer xenograft model. Lung Cancer 88: 1-8, 2015.

7. Raffa RB: Cancer 'survivor-care': I. the $\alpha 7 \mathrm{nAChR}$ as potential target for chemotherapy-related cognitive impairment. J Clin Pharm Ther 36: 437-445, 2011.

8. Tu CC, Huang CY, Cheng WL, Hung CS, Chang YJ and Wei PL: Silencing A7-nAChR levels increases the sensitivity of gastric cancer cells to ixabepilone treatment. Tumour Biol 37: 9493-9501, 2016.

9. Sun $\mathrm{H}$ and Ma X: $\alpha 5-n A C h R$ modulates nicotine-induced cell migration and invasion in A549 lung cancer cells. Exp Toxicol Pathol 67: 477-482, 2015.

10. Wang JC, Cruchaga C, Saccone NL, Bertelsen S, Liu P, Budde JP, Duan W, Fox L, Grucza RA, Kern J, et al: Risk for nicotine dependence and lung cancer is conferred by mRNA expression levels and amino acid change in CHRNA5. Hum Mol Genet 18: 3125-3135, 2009.
11. Jia $Y$, Sun $H$, Wu H, Zhang H, Zhang X, Xiao D, Ma $X$ and Wang Y: Nicotine inhibits cisplatin-induced apoptosis via regulating $\alpha 5-\mathrm{nAChR} / \mathrm{AKT}$ signaling in human gastric cancer cells. PLoS One 11: e0149120, 2016.

12. Silva JM, Bulman C and McMahon M: BRAFV600E cooperates with PI3K signaling, independent of AKT, to regulate melanoma cell proliferation. Mol Cancer Res 12: 447-463, 2014.

13. Hwang CS, Prieto VG, Diwan AH, Lizee G, Ellerhorst JA, Ekmekcioglu S, Liu P, Eton O, Kinney SA, Grimm EA, et al: Changes in pERK1/2 and pAKT expression in melanoma lesions after imatinib treatment. Melanoma Res 18: 241-245, 2008.

14. Jiang L, Campagne C, Sundstrom E, Sousa P, Imran S, Seltenhammer M, Pielberg G, Olsson MJ, Egidy G, Andersson L and Golovko A: Constitutive activation of the ERK pathway in melanoma and skin melanocytes in Grey horses. BMC Cancer 14: 857,2014

15. Trisciuoglio D, Iervolino A, Zupi G and Del Bufalo D: Involvement of PI3K and MAPK signaling in bcl-2-induced vascular endothelial growth factor expression in melanoma cells. Mol Biol Cell 16: 4153-4162, 2005.

16. Wang J, Yang Z, Wen J, Ma F, Wang F, Yu K, Tang M, Wu W, Dong Y, Cheng X, et al: SKLB-M8 induces apoptosis through the AKT/mTOR signaling pathway in melanoma models and inhibits angiogenesis with decrease of ERK1/2 phosphorylation. J Pharmacol Sci 126: 198-207, 2014.

17. Jazirehi AR, Wenn PB and Damavand M: Therapeutic implications of targeting the PI3Kinase/AKT/mTOR signaling module in melanoma therapy. Am J Cancer Res 2: 178-191, 2012.

18. Livak KJ and Schmittgen TD: Analysis of relative gene expression data using real-time quantitative PCR and the 2(-Delta Delta C(T)) method. Methods 25: 402-408, 2001.

19. Liu S, Chaudhry MR, Berrebi AA, Papadimitriou JC, Drachenberg CB, Haririan A and Alexiev BA: Polyomavirus replication and smoking are independent risk factors for bladder cancer after renal transplantation. Transplantation 101: 1488-1494, 2017

20. Sharp L, Johansson H, Hatschek T and Bergenmar M: Smoking as an independent risk factor for severe skin reactions due to adjuvant radiotherapy for breast cancer. Breast 22: 634-638, 2013.

21. Bhattacharyya S, Mandal S, Banerjee S, Mandal GK, Bhowmick AK and Murmu N: Cannabis smoke can be a major risk factor for early-age laryngeal cancer-a molecular signaling-based approach. Tumour Biol 36: 6029-6036, 2015.

22. Hickey K, Do KA and Green A: Smoking and prostate cancer. Epidemiol Rev 23: 115-125, 2001.

23. Kenfield SA, Stampfer MJ, Chan JM and Giovannucci E: Smoking and prostate cancer survival and recurrence. JAMA 305: 2548-2555, 2011.

24. Huncharek M, Haddock KS, Reid R and Kupelnick B: Smoking as a risk factor for prostate cancer: A meta-analysis of 24 prospective cohort studies. Am J Public Health 100: 693-701, 2010.

25. Honda GD, Bernstein L, Ross RK, Greenland S, Gerkins V and Henderson BE: Vasectomy, cigarette smoking, and age at first sexual intercourse as risk factors for prostate cancer in middle-aged men. Br J Cancer 57: 326-331, 1988.

26. Giovannucci E, Rimm EB, Ascherio A, Colditz GA Spiegelman D, Stampfer MJ and Willett WC: Smoking and risk of total and fatal prostate cancer in united states health professionals. Cancer Epidemiol Biomarkers Prev 8: 277-282, 1999.

27. Veierãd $M B$, Laake $P$ and Thelle DS: Dietary fat intake and risk of prostate cancer: A prospective study of 25,708 Norwegian men. Int J Cancer 73: 634-638, 1997.

28. Heikkilä R, Aho K, Heliövaara M, Hakama M, Marniemi J, Reunanen A and Knekt P: Serum testosterone and sex hormone-binding globulin concentrations and the risk of prostate carcinoma: A longitudinal study. Cancer 86: 312-315, 1999.

29. Spitz MR, Amos CI, Dong Q, Lin J and Wu X: The CHRNA5-A3 region on chromosome 15q24-25.1 is a risk factor both for nicotine dependence and for lung cancer. J Natl Cancer Inst 100: 1552-1556, 2008

30. Duga S, Soldà G, Asselta R, Bonati MT, Dalprà L, Malcovati M and Tenchini ML: Characterization of the genomic structure of the human neuronal nicotinic acetylcholine receptor CHRNA5/A3/B4 gene cluster and identification of novel intragenic polymorphisms. J Hum Genet 46: 640-648, 2001.

31. Valor LM, Campos-Caro A, Carrasco-Serrano C, Ortiz JA, Ballesta JJ and Criado M: Transcription Factors NF-Y and Sp1 are important determinants of the promoter activity of the bovine and human neuronal nicotinic receptor beta 4 subunit genes. J Biol Chem 277: 8866-8876, 2002. 
32. Vivanco I and Sawyers CL: The phosphatidylinositol 3-Kinase AKT pathway in human cancer. Nat Rev Cancer 2: 489-501, 2002.

33. Majumder PK and Sellers WR: Akt-regulated pathways in prostate cancer. Oncogene 24: 7465-7474, 2005.

34. Malik SN, Brattain M, Ghosh PM, Troyer DA, Prihoda T, Bedolla R and Kreisberg JI: Immunohistochemical demonstration of phospho-akt in high gleason grade prostate cancer. Clin Cancer Res 8: 1168-1171, 2002.

35. Kreisberg JI, Malik SN, Prihoda TJ, Bedolla RG, Troyer DA, Kreisberg S and Ghosh PM: Phosphorylation of Akt (Ser473) is an excellent predictor of poor clinical outcome in prostate cancer. Cancer Res 64: 5232-5236, 2004.

36. Graff JR, Konicek BW, McNulty AM, Wang Z, Houck K, Allen S, Paul JD, Hbaiu A, Goode RG, Sandusky GE, et al: Increased AKT activity contributes to prostate cancer progression by dramatically accelerating prostate tumor growth and diminishing p27Kip1 expression. J Biol Chem 275: 24500-24505, 2000 .
37. Lin HK, Yeh S, Kang HY and Chang C: Akt suppresses androgen-induced apoptosis by phosphorylating and inhibiting androgen receptor. Proc Natl Acad Sci USA 98: 7200-7205, 2001.

38. Yuge K, Kikuchi E, Hagiwara M, Yasumizu Y, Tanaka N, Kosaka T, Miyajima A and Oya M: Nicotine induces tumor growth and chemoresistance through activation of the PI3K/Akt/ mTOR pathway in bladder cancer. Mol Cancer Ther 14: 2112-2120, 2015

This work is licensed under a Creative Commons Attribution-NonCommercial-NoDerivatives 4.0 International (CC BY-NC-ND 4.0) License. 